\title{
Multiple bilateral pulmonary aspergillomata ${ }^{1}$
}

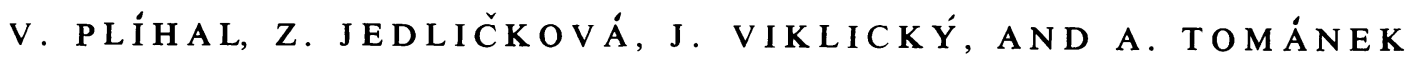 \\ From the Tuberculosis Research Institute and the Departments of Bacteriology and Pathology, \\ the Bulovka Hospital, Prague, Czechoslovakia
}

\begin{abstract}
An increasing number of cases of pulmonary aspergillosis have been reported in the last few years. Up to now about 200 cases of this disease have been described in various papers, the most frequent form of pulmonary aspergillosis being the aspergilloma, of which a full account is given by Villar, Pimentel, and Costa (1962). The majority of these papers were concerned with solitary aspergillomata, and only in a few of them were multiple granulomata described. The former were first reported by Hinson, Moon, and Plummer (1952) and later by Le Nouëne, Esquirol, and Ardaillou (1956). These authors described multiple, but unilateral, aspergillomata. Bilateral disease of this type was first mentioned by Lagèze, Bérard, Galy, and Touraine (1953). Seven other papers, mostly by French authors and covering bilateral multiple granulomata, were presented subsequently (Le Nouëne, Sarremejean, and Secousse, 1957 ; Quillec, 1958 ; Boulet, Harant, Mirouze, Rioux, Barjon, Bertrand, and Menard, 1958 ; Balgairies, Aupetit, and Lenoir, 1960; Vlakhov and Karparov, 1960 ; Meyer, Monod, Brunel, Brux, and Bourguignon, 1961 ; Rodrigues and Azeredo, 1961). However, in no case described so far has the total number of aspergillomata exceeded three in patients with either unilateral or bilateral disease. We do not think any patient has been reported with such a large number of bilateral pulmonary aspergillomata as we have described in the present paper.
\end{abstract}

\section{CASE REPORT}

The patient, a woman pensioner aged 62 , suffered from syphilis, which was found when she was 21 years old. Up to 1950 she had been given about 10 courses of antiluetic therapy. At the age of 24, pleurisy was discovered on the right side, and she was treated for six weeks at home. She suffered from chronic progressive polyarthritis from 1938, for which she was repeatedly treated in the Department for Internal Diseases and Rheumatology with salicylates and gold-containing drugs. The patient later admitted

1 Presented on 4 November 1961 at a meeting of the Phthisiologists and Pneumologists Section of the J. E. Purkyner Medical Association in Prague to taking cortisone for a long time without medical supervision and control. In 1950 she developed bilateral ulcera cruris which were identified by a specialist in dermato-venereology as syphilis gummosa cruris. Because of this aetiology she was repeatedlyo treated until 1958 with penicillin in a total dose of 30 million units. The treatment resulted in scarred $\overrightarrow{-}$ healing on both legs. The patient was registered from 1955 at a tuberculosis dispensary because of alleged minimal specific healed pulmonary disease at the left ${ }^{\supset}$ apex. She was admitted to the Tuberculosis Research $\overrightarrow{0}$ Institute at the beginning of 1961 because of an unusual pulmonary finding detected during a mass radiography campaign in December 1960.

On admission on 1 February 1961 the patient complained of pains in the joints, lasting for years, and of considerable difficulty in walking: otherwise sheڤ had only some cough with mucoid sputum.

Clinical examination revealed striking changes $\Rightarrow$ caused by severe progressive polyarthritis. The affected응 joints of the upper and lower extremities were deformed and painful with greatly reduced mobility. The frontal sides of both shins were covered with scars and pigmentation which had developed during healing of the ulcerous disease. No abnormal sounds were heard over either lung except for a few signs of $\stackrel{\otimes}{\times}$ bronchitis. The patient produced about 5 to $10 \mathrm{ml}$. $\overline{0}$ of slightly mucoid sputum. Mycobacterium tuberculosis could not be detected either by microscopy or on culture in 17 samples collected at various time 3 intervals after her admission to hospital. The tempera- 0 ture did not exceed the normal range; the E.S.R. was found to be $96 \mathrm{ml}$./hour and $126 \mathrm{ml}$./2 hours. The $D$ blood picture showed slight anaemia $(3,340,000)$. R.B.C./c.mm.) together with leucocytosis $(12,000 / \mathrm{N}$ c.mm.). Bordet-Wassermann reactions were negative, but the treponemal immobilization test yielded a $N$ positive result.

The initial film of the chest (Fig. 1) showed, in addition to bilateral thickening of the pleura in the apices, a calcified primary complex in the right lower $\stackrel{\circ}{\simeq}$ zone, and a diaphragmatic adhesion on the right side, $\mathbb{D}$ a total of six thin-walled round cavities from 2 to $4 \mathrm{~cm}$. in size located in both upper and the right midzones. These cavities were almost completely filled by

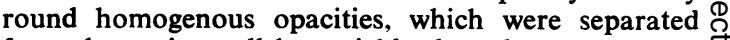
from the cavity wall by a sickle-shaped narrow trans- $\overrightarrow{\mathbb{D}}$ lucent area and they were connected to the cavity wall by a relatively bright stem. The largest cavity was situated in the right mid-zone. The pathological o 


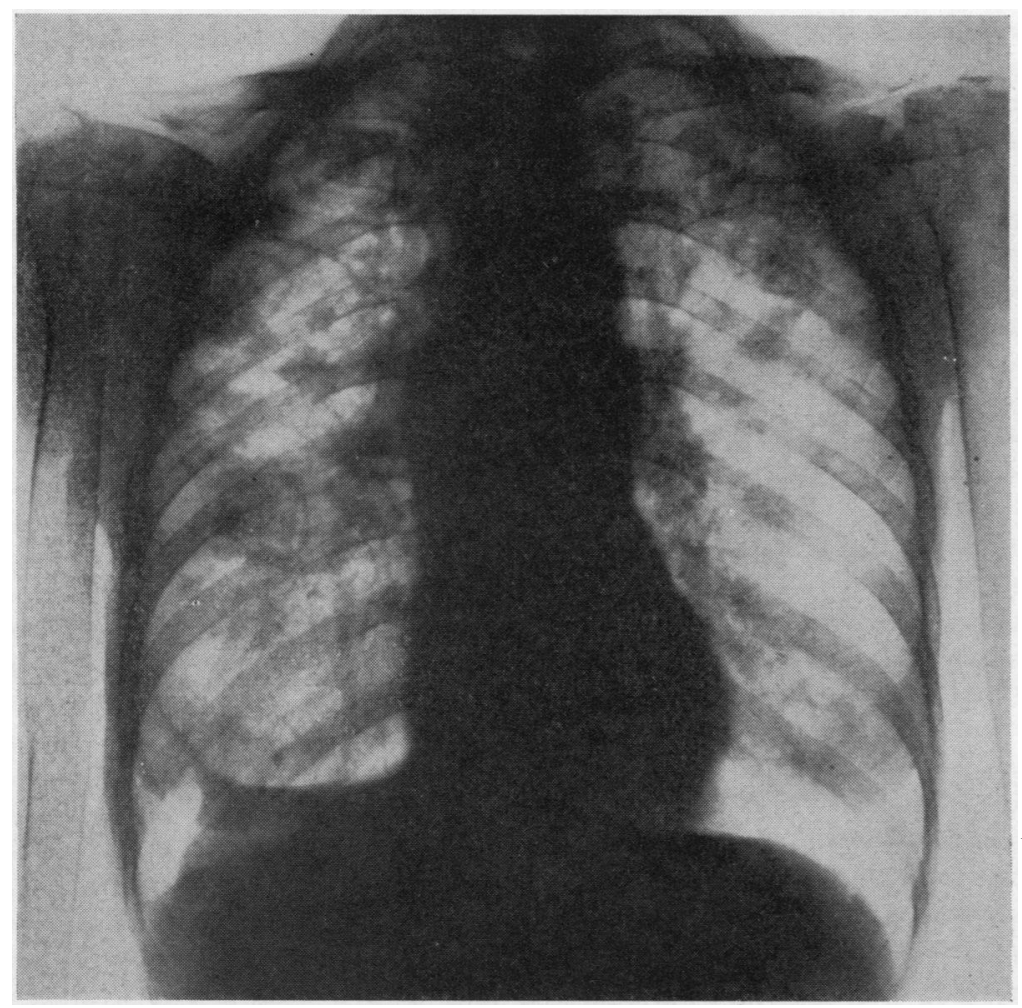

FIG. 1. Radiograph at the time of admission to hospital.

changes described were seen more clearly on tomograms (Figs. 2 to 5), particularly in the 6 to $9 \mathrm{~cm}$. cuts, where, in addition to these partly-filled cavities, there were two smaller round solid shadows 1.5 to $2 \mathrm{~cm}$. in size without any translucency in both lungs.

From this clear tomographic picture of the disease, we suspected that the patient might be suffering from pulmonary aspergillosis, especially when repeated small haemoptyses occurred spontaneously. Bronchoscopic examination was not possible because of greatly decreased mobility of the cervical spine. Bronchographic examination revealed no bronchiectatic changes, nor was it possible to fill the cavities (Fig. 6).

\section{BACTERIOLOGY}

Microscopical examination and culture of the sputum for fungi was at first negative. Only after repeated examination of specimens collected directly from the cavity and of specimens obtained by bronchial lavage with physiological saline, was it possible to demonstrate the aspergilli by microscopy or on culture in seven subsequently collected specimens.

Aspergilli were first demonstrated in the sputum of this patient in 1958, when she was admitted to the Department of Dermatology. During her stay at the Tuberculosis Research Institute aspergilli were found in the sputum seven times during April and May 1961. Under sterile conditions collected samples were seeded on a number of media (blood agar, Endo agar, liquid and solid media for anaerobic cultivation, Littman and Czapek-Dox media, liquid and solid Sabouraud media). Special media supporting a growth of yeast were incubated at $37^{\circ} \mathrm{C}$. as well as at room temperature. Growth was obtained mainly on Sabouraud media after 48 hours of incubation at $37^{\circ} \mathrm{C}$. The size of the colonies increased gradually, achieving a mean diameter of $1 \mathrm{~cm}$., and after one week of incubation the whole surface of the medium was covered with a confluent growth of colonies, sandy in colour and whitish underneath. Later, the upper layers of the colonies consisted of a dense filamentous structure, green in colour, which subsequently changed to brown after three weeks' incubation. They developed a leathery surface and were firmly connected with the underlying medium. A detailed mycological examination was carried out by Professor G. H. de Vries, who identified the 


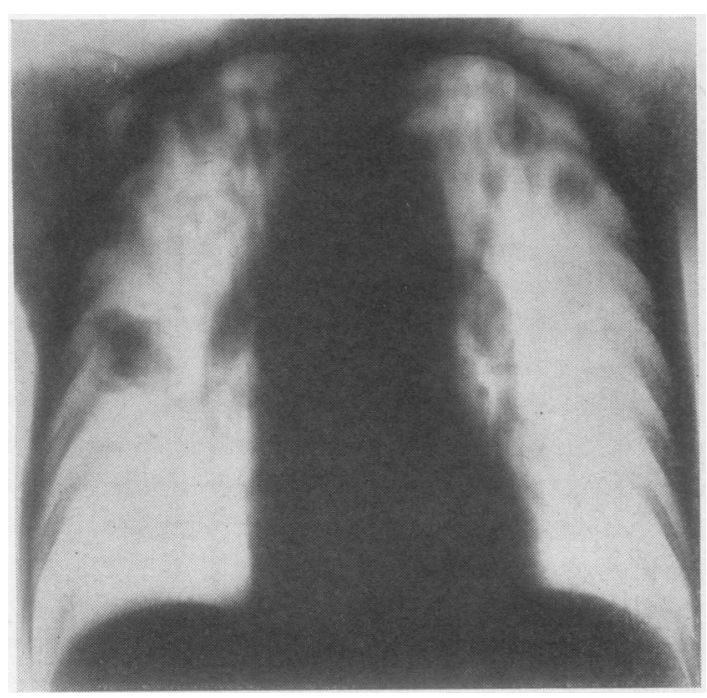

FIG. $2.6 \mathrm{~cm}$.

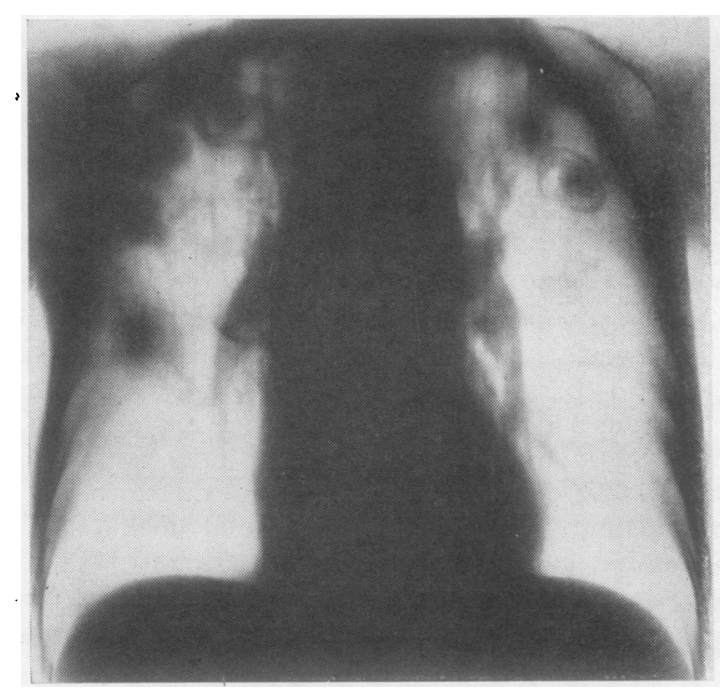

FIG. $4.8 \mathrm{~cm}$.

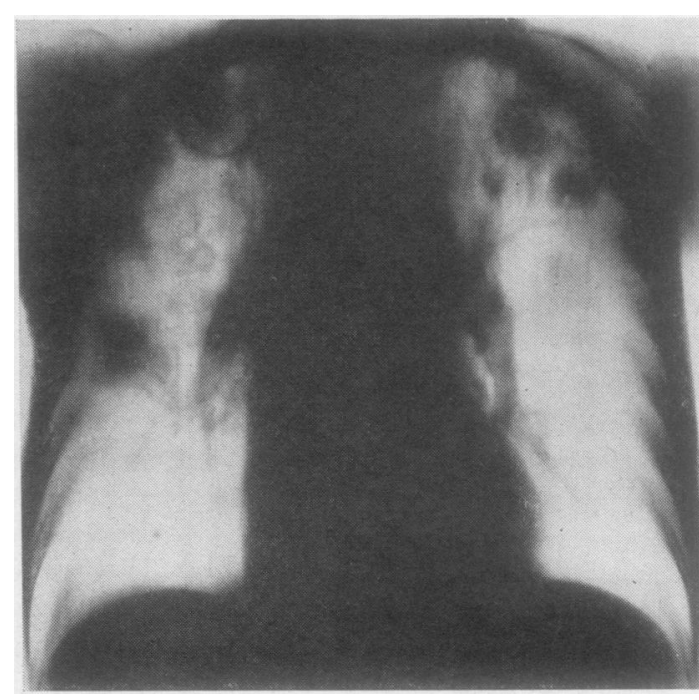

FIG. $3.7 \mathrm{~cm}$.

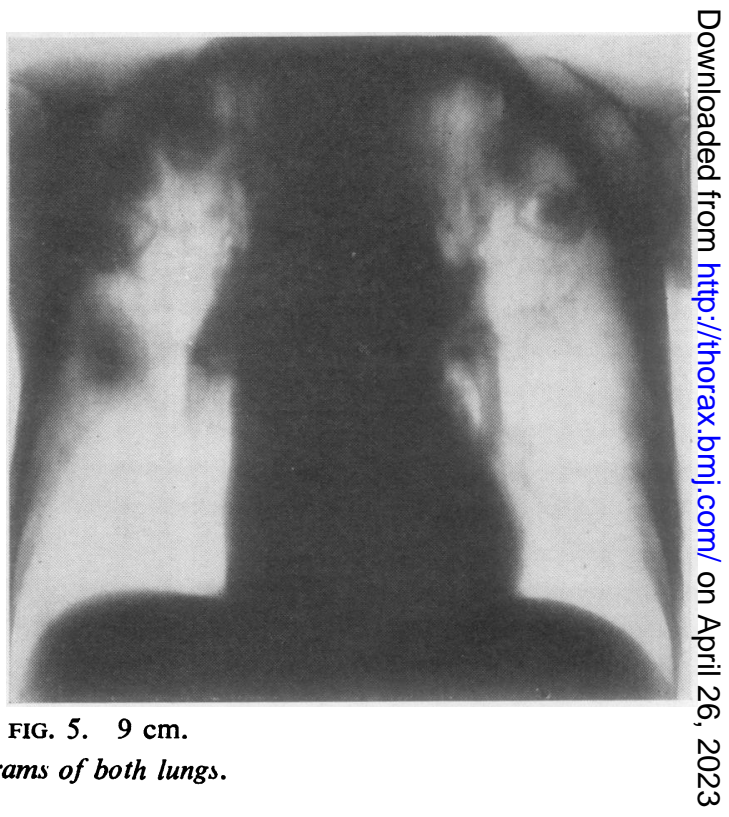

only a few colonies were grown from the lungs. Subsequently mice were infected intraperitoneallye with $0.5 \mathrm{ml}$. of the same suspension as the rabbit.\$s Aspergilli were detected in the lungs, spleen, liver: kidney, and heart.

No symptoms of disease were seen in infected mice or rabbits up to 15 to 20 days after infection $\frac{?}{\mathbb{D}}$ Histological examination of the lungs, spleen, livero kidneys, and brain from mice revealed no patho logical changes. In rabbits, however, granulomatos were detected in the lungs, with central areas cono with tissue homogenate from the spleen, whereas 


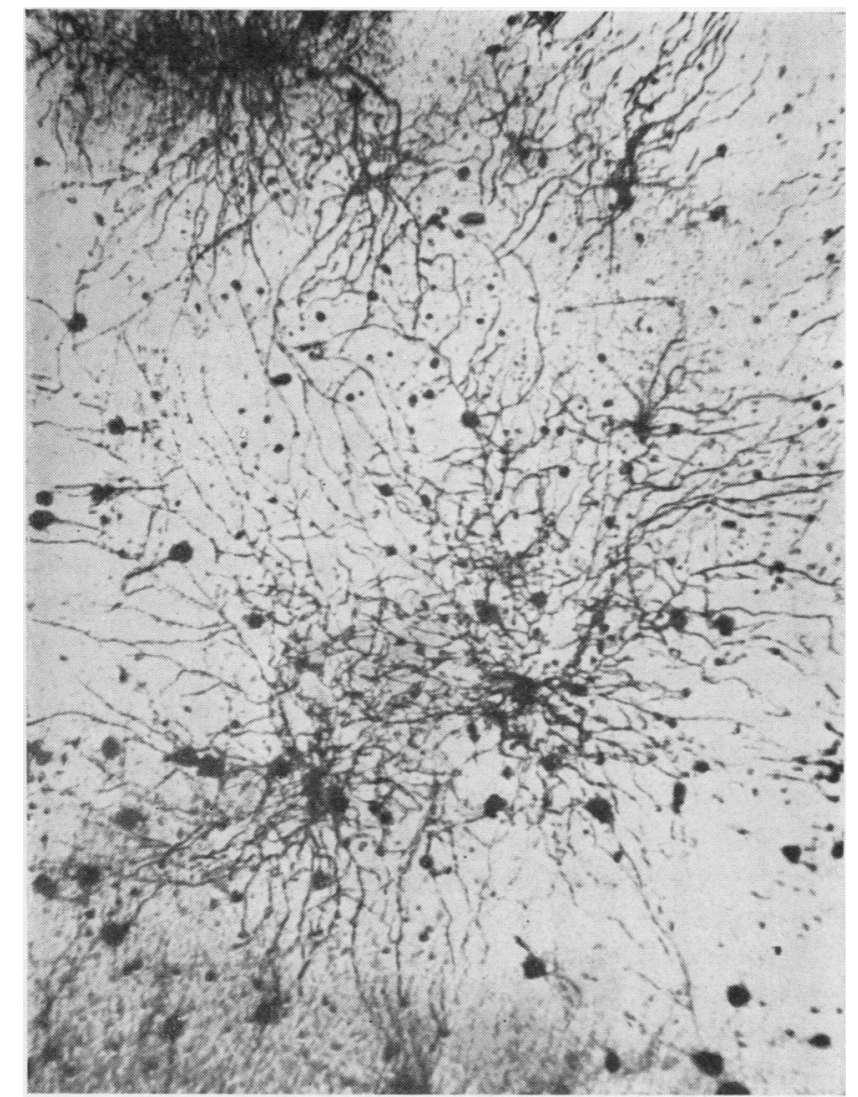

FIG. 7
FIG. 6. Bronchogram of the right lung.

FIG. 7. Aspergillus terreus Thom on corn agar ( $\times 30)$.

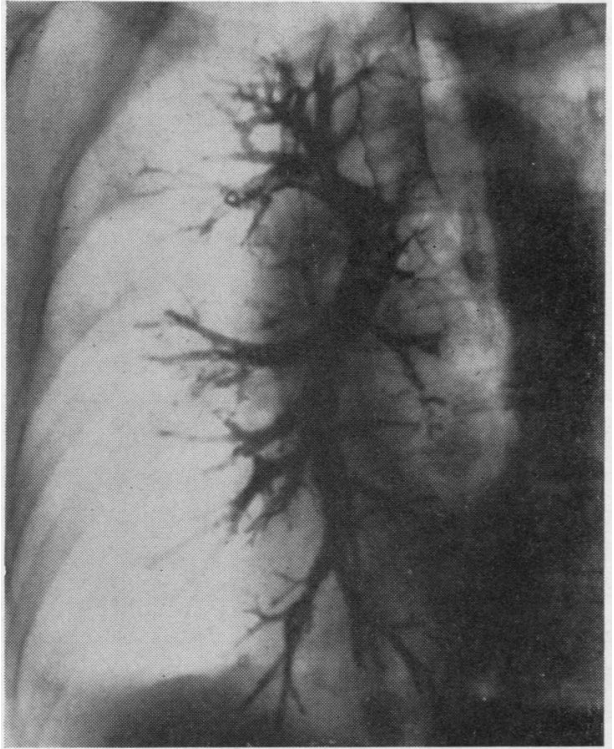

FIG. 6.

FIG. 8. Aspergillus terreus Thom on corn agar $(\times 200)$. 


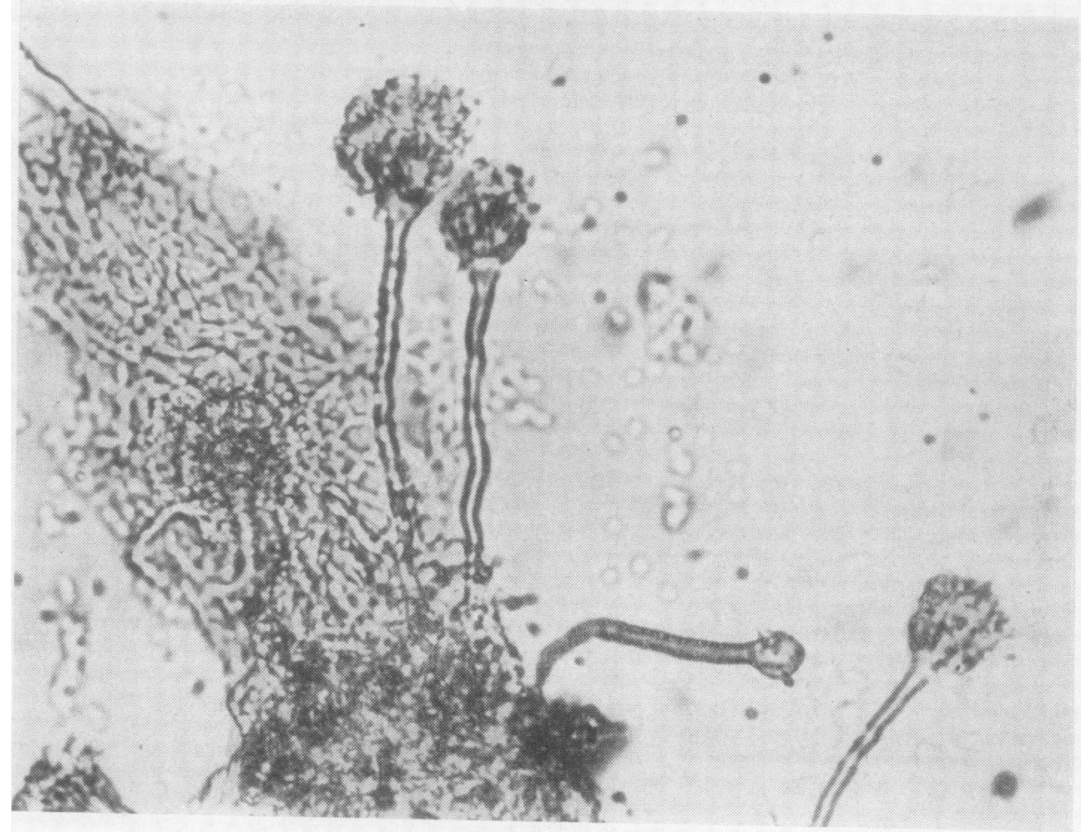

FIG. 9. Smear of aspergilli (conidiophores with vesicles and chains of conidia appearing on sterigmata, $\times 200)$.

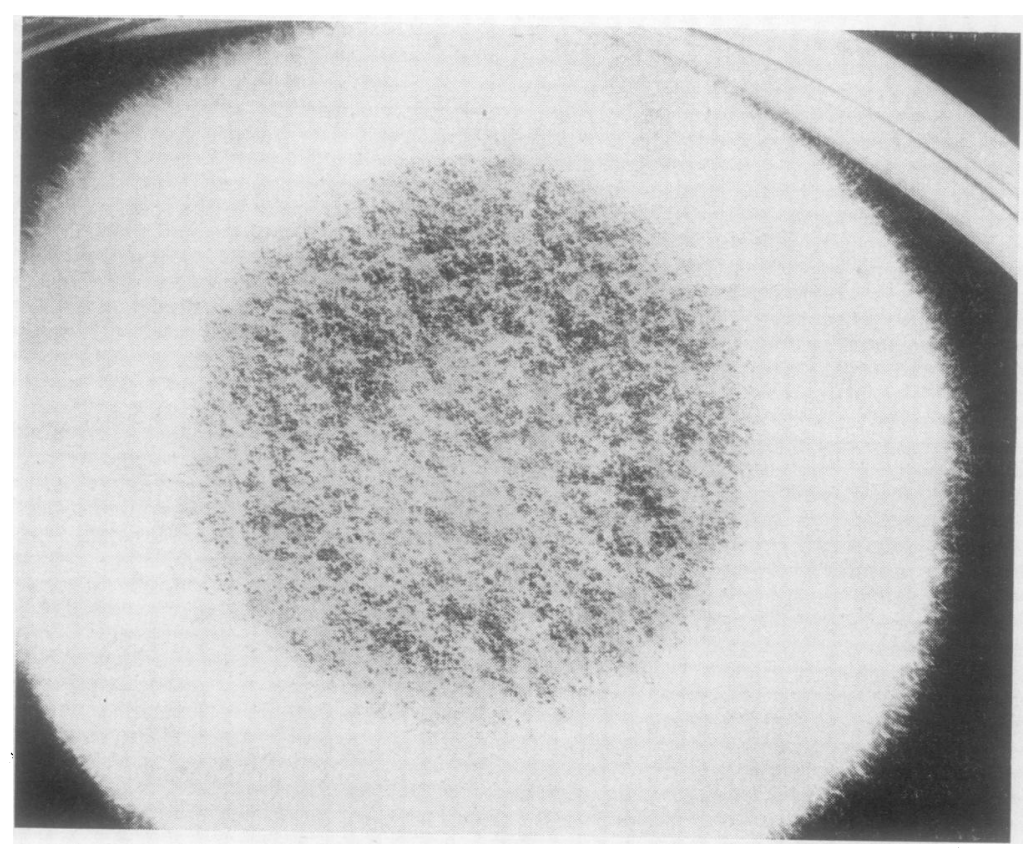

FIG. 10. 'Five-day-old culture of aspergilli on Czapek-Dox medi:ım $(\times 2 \cdot 5)$. 


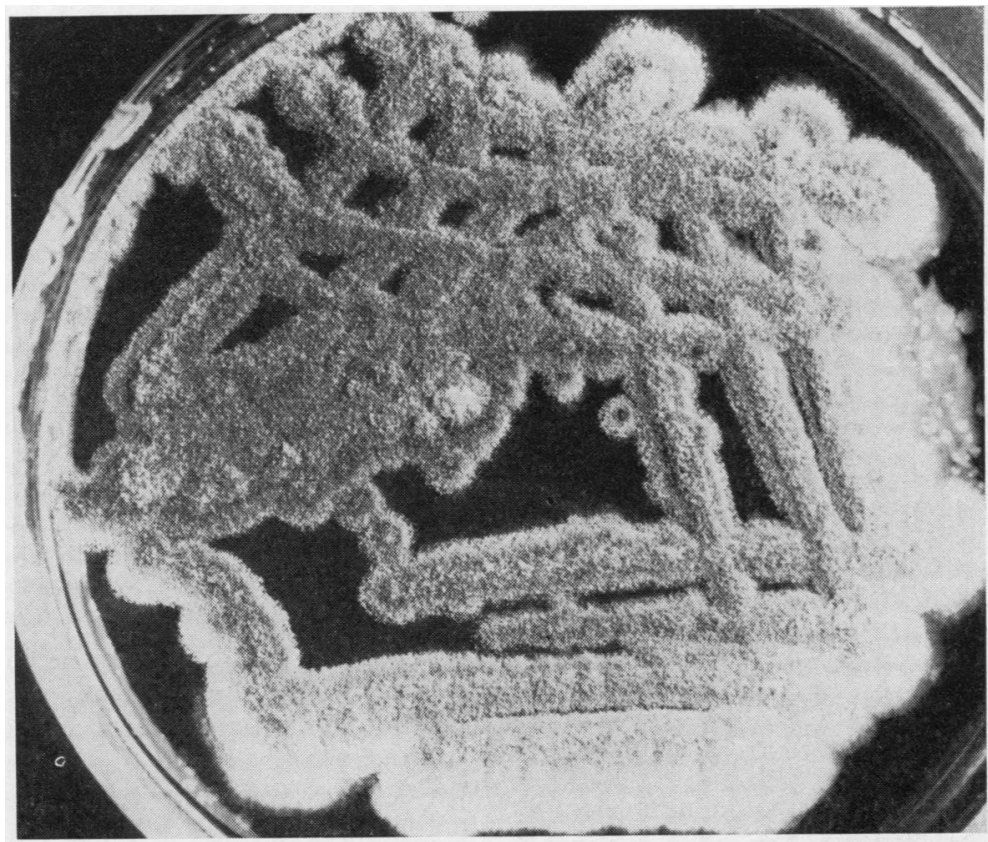

FIG. 11. Ten-day-old sub-culture of Aspergillus terreus Thom, isolated from sputum, on Littman's medium $(\times 1 \cdot 2)$.

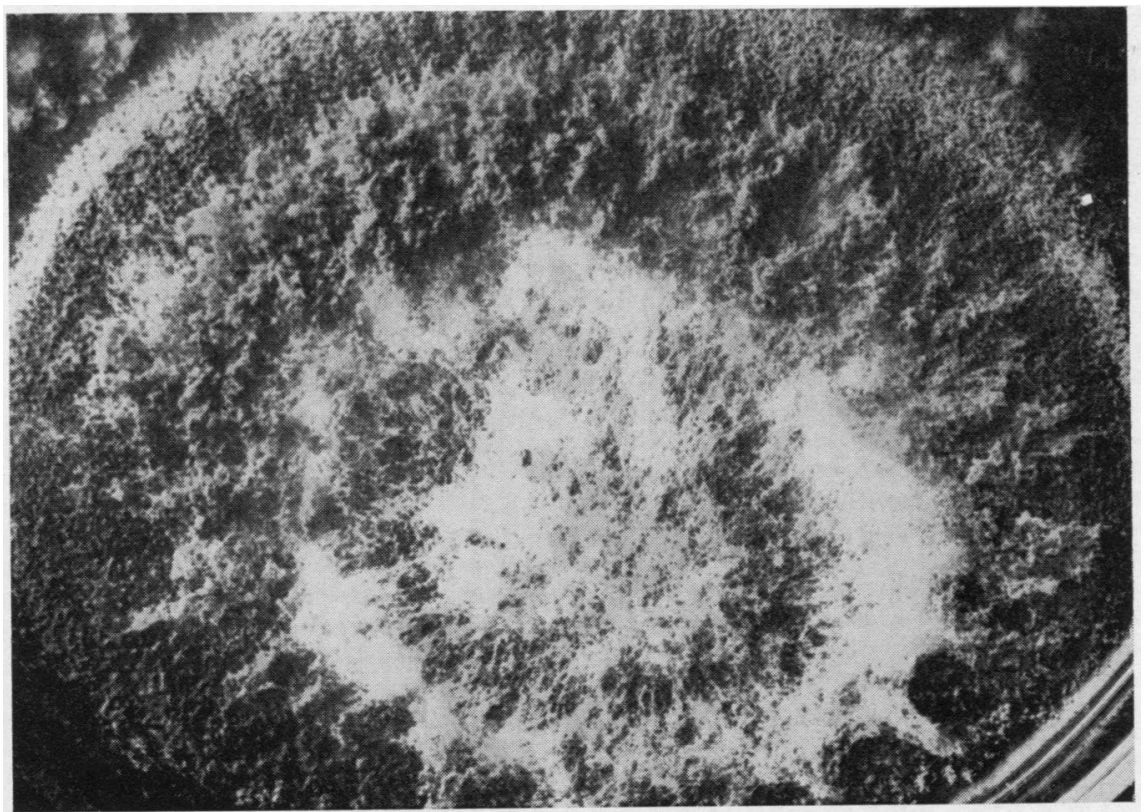

FIG. 12. Seven-day-old culture of Aspergillus terreus Thom, isolated from rabbit spleen, on Littman's medium $(\times 2 \cdot 2)$. 
taining a few mycelial fragments surrounded by numerous eosinophilic leucocytes accompanied by lymphocytes and large macrophages. In some cases central necrosis could be seen in this animal, and a number of granulocytes were noted at the same time. The granulomata were always situated in perivascular areas, and the adjacent bronchi showed slight inflammation. Similar granulomata with numerous eosinophilic leucocytes were also seen in the liver, but no mycelial fragments or other microscopic signs of fungi were detected. All other viscera showed no pathological change.

\section{TREATMENT}

After the diagnosis had been proved by means of bacteriological investigations, the patient was treated at first orally with a $10 \%$ solution of potassium iodide. When the sensitivity of the aspergillus to antimycotic drugs was known, amphotericin-B (Fungizone (R), Squibb) in intravenous infusions was also given. A total of 15 infusions were administered, but they were discontinued because the patient could not tolerate this drug. After the infusion, the patient almost always developed a tremor and vomiting, as well as venous thrombosis in the area where the infusion had been administered. Because of this, the therapy was continued by administering only the oral potassium iodide solution together with isoniazid, which was given to the patient for preventive purposes from the beginning of her stay in hospital.

Control tomograms showed no regression of the pathological changes in the lungs after chemotherapy either with potassium iodide or when combined with amphotericin-B.

The patient was therefore sent home with a recommendation to continue treatment with potassium iodide. On discharge she felt subjective improvement, but apart from a considerable reduction in the amount of expectoration her clinical state was not really any different from when she was admitted. Aspergilli were found continuously in sputum specimens. Control investigations in February 1962 revealed no changes in the radiographic picture, but aspergilli were found in the sputum at this time.

\section{DISCUSSION}

Most aspergilli are saprophytic microbes, so that, in spite of their widespread distribution in nature, pulmonary infections in man are relatively rare. Usually, $\boldsymbol{A}$. fumigatus, $\boldsymbol{A}$. niger, $\boldsymbol{A}$. nidulans, and $A$. flavus are claimed to possess certain patho- genic properties. The mode of transfer of the infection as well as the incubation time are not known. Aspergilli are often detected in bacteriology laboratories as contaminants of other bacterial $\vec{D}$ cultures. Therefore an important question is 응 whether the finding of mycotic elements in a speci- $\oplus$ men can necessarily be correlated with a patho- $\overrightarrow{0}$ logic finding in a given patient. However, we feel that the repeated presence of fungi in the sputum of our patient suggests this possibility here.

Pulmonary aspergillosis may be divided into the type which will spread throughout the trachea and bronchi, and that which is localized to the lungs and forms demarcated pathological changes. In both types the development is in close correlation with decreased resistance of the organism, so that most cases will be found in long-term wasting diseases, such as tumours, tuberculosis, and blood dyscrasias. More recently, the long-term administration of antibiotics and corticosteroids has undoubtedly contributed to their occurrence (Sidransky and Friedman, 1959; Torack, 1957 ; Welsh and Buchness, 1955; Levy and Cohen, 1955).

The type of pulmonary aspergillosis most often seen is the demarcated pathological lesion that is now known as aspergilloma. This type of the disease is in fact formed by packs of aspergillus mycelia, which fill in pulmonary cavities by forming small or sometimes even large round masses without spreading into the surrounding tissue.

The pathogenesis of cavitation in pulmonary aspergillosis is not yet agreed by all workers. Some investigators, such as Monod, Pesle, and Ségrétain (1951) and Pesle (1956), are of the opinion that the cavity is formed after the lodging of the fungi, and that it is caused by the pressure of the increasing mycotic mass within the lumina of the bronchi, so that the aspergilloma itself represents the factor provoking the formation of bronchiectatic lesions. Other authors, however, think it more likely that localization and multiplication of $N$ aspergilli take place in a pre-formed cavity occurring as the result of previous disease.

The radiographic picture of an aspergilloma shows a round or oval shadow of homogeneous density, some 2 to $5 \mathrm{~cm}$. in size. Aspergilli are 0 usually localized in thin-walled cavities, mostly in the upper lobes, more often in the right lung. ? In particular the tomographic picture of a pul- $\square$ monary aspergilloma is typical, as emphasized by most investigators. The sponge-like mass of fungi is in this case of homogeneous density and it is $\mathbb{D}$ separated from the cavity wall by a narrow translucent area. Sometimes the radiographic findings 
are less typical: the aspergilloma may form a round opacity without any surrounding translucency or, conversely, it may represent only a small part of a bullous formation.

Resection is the only rational therapy in such a case, since conservative treatment will often fail to cure the disease.

Our patient suffered from bilateral multiple pulmonary aspergillomata localized in both upper and in the right lower lobes, and aspergilli were repeatedly found in sputum specimens. Her history included syphilis, which had been treated previously but evidently inadequately, as shown by the ulceration on the shins. These were then repeatedly treated with penicillin. The patient also took cortisone for a long time because of progressive polyarthritis.

The aetiology of these cavities filled with aspergillomata remains obscure. Bronchiectatic lesions could not be demonstrated by bronchography, and tuberculous or abscess origin is hardly supported either by the history or by the clinical and radiographic picture of the disease. We could, of course, still consider the idea of cavities developing in syphilitic pulmonary lesions, because of the lesions observed on the shins. Summarizing all the aetiological possibilities, perhaps the previously mentioned conception of Monod and Pesle is the most probable in this case.

It is quite possible that the long-term administration of antibiotics in a patient suffering from three different diseases (syphilis, progressive polyarthritis, and pulmonary aspergilloma) with a consequently decreased resistance of the organism played an important role in the pathogenesis of the mycotic disease.

\section{SUMMARY}

A woman aged 62 suffered from bilateral multiple pulmonary aspergillomata with concurrent progressive polyarthritis and syphilis; for both the latter diseases she had been treated for a long time with cortisone and penicillin. The diagnosis of aspergillosis is based on the repeated finding of aspergilli in the sputum both by microscopy and on culture, together with a characteristic radiographic picture. The strain of fungi was identified as Aspergillus terreus Thom. The stimulating influence of cortisone and penicillin on the subsequent development of a mycotic disease in a subject with a decreased resistance to infection is emphasized.

The authors are much indebted to Professor Dr. G. A. de Vries, Centraalbureau voor Schimmel- cultures, Baarn, Holland, for identifying the Aspergillus strain.

\section{REFERENCES}

Balgairies, J., Aupetit, J., and Lenoir, L. (1960). Aspergillomes intracavitaires chez les pneumoconiotiques. Poumon, 16, 253.

Boulet, P., Harant, H., Mirouze, J., Rioux, J., Barjon, P., Bertrand, A., and Menard, A. (1958). Aspergillome pulmonaire secondaire à forme bilatérale et "ectasiante". Sem. Hôp. Paris, 34, 99.

Hinson, K. F. W., Moon, A. J., and Plummer, N. S. (1952). Bronchopulmonary aspergillosis. Thorax, 7,317 .

Lagèze, P., Bérard, M., Galy, P., and Touraine, R. (1953). Le mégamycétome pulmonaire ou aspergillome intra-cavitaire à propos de trois cas. J. franc. Méd. Chir. thor., 7,648 .

Le Nouëne, J., Esquirol and Ardaillou (1956). Aspergillome bronchectasiant multiple (3 localisations). Presse méd., 64, 974.

Sarremejean, P., and Secousse, J. P. (1957). Aspergillomes bilatéraux. J. franc. Méd. Chir. thor., 11, 274.

Levy, E. S., and Cohen, D. B. (1955). Systemic moniliasis and aspergillosis complicating corticotropin therapy. A.M.A. Arch. intern. Med., 95, 118 .

Meyer, A., Monod, O., Brunel, M., Brux, J. de, and Bourguignon, D. (1961). Deux cas d'aspergillomes bronchiques vraisemblablement secondaires dont un a localisation bilatérale traité chirurgicalement en un seul temps. J. franc. Méd. Chir. thor., 15, 533.

Monod, O., Pesle, G., and Ségrétain, G. (1951). L'aspergillome bronchectasiant. Presse méd., 59, 1557.

Pesle, G. D. (1956). Évolution de l'aspergillome bronchectasiant, à propos de 4 cas. Ibid., 64, 1563.

Quillec, P. (1958). A propos d'un cas d'aspergillomes bilatéraux secondaires. J. franc. Méd. Chir. thor., 12, 228.

Rodrigues, F., and Azeredo, I. (1961). Aspergillomes géants et bilatéraux développés dans des cavités bulleuses. Rev. Tuberc. (Paris), 25, 433.

Sidransky, H., and Friedman, L. (1959). The effect of cortisone and antibiotic agents on experimental pulmonary aspergillosis. Amer. J. Path., 35, 169.

Torack, R. M. (1957). Fungus infections associated with antibiotic and steroid therapy. Amer. J. Med., 22, 872 .

Villar, T. G., Pimentel, J. C., and Costa, M. F. E. (1962). The tumourlike forms of aspergillosis of the lung (pulmonary aspergilloma). Thorax, 17, 22.

Vlakhov, K., and Karparov, M. (1960). Aspergillome pulmonaire bilatéral et monilliomes pulmonaires. J. Radiol. Électrol., 41, 34 Welsh, R. A., and Buchness, J. M. (1955). Aspergillus endocarditis, myocarditis and lung abscesses. Amer. J. clin. Path., 25, 782.

\section{ADDENDUM}

The patient has since died (12 August 1963). In the lungs no metastases were seen. In both lungs, but mainly in the right, a system of thin-walled cavities connected with the bronchi was found. There was fibrosis around the bronchi, dispersed fibro-anthracotic lesions, mainly in the apices, and calcification of the nodes. In addition to this, caseous nodules of a tuberculous nature were seen. Macroscopically, all the cavities were empty. Histological examination showed these cavities to be bronchiectatic with inflammatory changes in the walls, sporadic weak granulation, and isolated huge cells; there were no specific lesions in the walls.

$A$. terreus Thom was cultivated from the lungs, the bronchi, and the deltoid muscle post mortem. The type was the same as in cultures from sputa obtained intra vitam.

It must be assumed that from her last examination in February 1962, when she had her last chest film, until death the patient had expectorated the contents of the cavities. She had never been employed in industry or worked in an environment exposed to dust. 